\title{
Fatores motivacionais ao tratamento de usuários de cocaína/crack em um hospital terciário em Porto Alegre/RS
}

\author{
Motivational factors to treatment of cocaine / crack in \\ a tertiary hospital in Porto Alegre / RS
}

\author{
Jacqueline Espindola Castro ${ }^{1}$ \\ Adriana Froener ${ }^{2}$ \\ Isabela Alves Rodrigues ${ }^{2}$ \\ Paula Cilene Pereira dos Santos ${ }^{3}$ \\ Marcello Ávila Mascarenhas ${ }^{3,4}$
}

\section{RESUMO}

O objetivo deste estudo foi investigar os fatores motivacionais ao tratamento de usuário cocaína/crack atendidos em um Hospital Terciário de Porto Alegre. A pesquisa foi de caráter transversal através da coleta de dados por meio de uma entrevista, acerca do uso/abuso de cocaína/crack e fatores associados, com indivíduos $(n=9)$ em tratamento no centro de dependência química de um Hospital Terciário de Porto Alegre do Rio Grande do Sul, no período de junho de 2011 até setembro de 2011. Os dados obtidos foram expressos de forma descritiva. Os achados demonstraram que amostra correspondia ao sexo masculino com idade média de 29,77 e desvio padrão de 7,58 anos, sendo que a maioria (50\%) se autodenominava brancos, 56\% solteiros, $56 \%$ com ensino fundamental e $56 \%$ sem ocupação renumerada. O principal achado foi que $67 \%$ apresentaram primeiro contato com a droga na faixa de 10 até 15 anos de idade e que obtenção foi através de assalto (32\%) e da família (27\%) com custos pessoais. Portanto, o estudo mostra fatores importantes no uso e abuso da cocaína/ crack.

\section{PALAVRAS-CHAVE}

Cocaína/crack. Comportamento aditivo. Família. Usuários de drogas. Dependente químico.

\footnotetext{
${ }^{1}$ Acadêmica do Curso de Biomedicina do Centro Universitário Metodista-IPA.

2 Programa de Pós Graduação em Biociências e Reabilitação do Centro Universitário Metodista-IPA.

3Professor do Curso de Biomedicina do Centro Universitário Metodista-IPA.

${ }^{4}$ Programa de Pós Graduação em Biociências e Reabilitação do Centro Universitário Metodista-IPA.
} 


\section{ABSTRACT}

The objective of this study was to investigate the factors of adherence to treatment of user cocaine/crack treated at a Tertiary Hospital in Porto Alegre. The research was a transversal study through the collection of data by means of an interview, about the use/abuse of cocaine/crack and factors associated with individuals $(n=9)$ in treatment at the center for chemical dependence in a Tertiary Hospital in Porto Alegre," Rio Grande do Sul, in the period from June 2011 to September 2011. The data obtained were expressed in a descriptive way. The findings showed that sample corresponded to males with a mean age of $29.77 \pm$ and standard deviation of 7.58 years, and the majority (50\%) called himself white, 56\% were unmarried, 56\% with primary school and $56 \%$ without occupation renumbered. The main finding was that $67 \%$ had their first contact with the drug in the range of 10 to 15 years of age and that was through assault (32\%) and family (27\%) with personal costs. Therefore, the present study shows important factors in use and abuse of cocaine/crack.

\section{KEYWORDS}

Cocaine crack. Craving. Family. drug users. Chemical dependency. 


\section{INTRODUÇÃO}

O consumo de drogas ilícitas vem crescendo em nossa população, isto tem contribuído para o aumento do número da violência e de homicídios. Em 2004, 185 milhões de pessoas $(4,7 \%)$ faziam uso destas substâncias, já em 2006, foram detectados 200 milhões (5\%) de pessoas na população mundial que faziam uso de substâncias ilícitas, sendo que 0,3\% eram usuários de crack (GALLASSI et al., 2008). Guimarães (2008) demonstrou que $46 \%$ dos usuários de cocaína/crack, acompanhados após doze meses de internação, não apresentaram melhora na dependência, sendo que $10 \%$ morreram por diversos motivos e 7\% cometeram algum delito e foram presos (GUIMARÃES, 2008).

Em 2012 a região Nordeste abrigou a maior parte dos usuários com 1,29\%, seguida pela região Sul com 1,05\% (OBID, 2014). Uma pesquisa realizada com estudantes no ano de 2012 demonstrou que $35,5 \%$ dos estudantes já haviam usado drogas ilícitas uma vez na vida. Destes, $6,4 \%$ usaram crack nos últimos 30 dias que antecederam a pesquisa, além disso, $0,5 \%$ dos estudantes do $9^{\circ}$ ano do ensino fundamental relataram ter usado crack neste período (PENSE, IBGE 2012).

No Sul, o consumo de drogas como maconha, anfetaminas, solventes, medicamentos como barbitúricos entre outros (excluindo apenas álcool e tabaco) perfaz um faixa de $17,1 \%$, no entanto o consumo exclusivamente de cocaína/crack é de 3,6\%, somente na forma de crack (fumada). Também a região Sul, dentre todas as regiões brasileiras apresenta a maior prevalência de "uso na vida" de cocaína aspirada ou de crack (CEBRID, 2007).

Um estudo realizado em quatro grandes cidades do Brasil, entre as quais está Porto Alegre, demonstra que a cocaína/crack é responsável por $39,4 \%$ dos atendimentos em hospitais por complicações relacionadas ao uso de da droga (KESSLER e PECHANSKY, 2008).

O consumo do crack acontece normalmente após um longo período de uso de outras substâncias psicoativas, e estas pessoas são geralmente poliusuárias de drogas lícitas como o álcool e o tabaco, que aparecem na maioria dos casos (JORGE et al., 2013). A família também é vista como uma das principais motivadoras à recaídas, pois as relações familiares são conflituosas e regadas por muitos ressentimentos (PAULA et al., 2014). A manipulação das pessoas próximas é bastante relatada pelos usuários em momentos de fissura, os usuários têm o perfil mentiroso e manipulador, são conscientes deste estado, o que faz com que eles percam a confiança das pessoas que convivem com eles (CHAVES et al., 2011). Os usuários de crack acabam sofrendo por causa da perda dos vínculos familiares, que acabam se perdendo por tentativas frustradas de ajuda, e tendem a desistir de apoiar o usuário que muitas vezes é expulso de casa o que dificulta o tratamento (PAULA et al., 2014).

No entanto, vivemos em uma sociedade que cultua o prazer imediato, em que tudo se torna descartável, necessitando de novos acontecimentos continuamente. Este fato é mostrado pelo apelo comercial e, com o crack não foi diferente, assim que foi aparecendo foi despertando curiosidade nos usuários (JORGE et al., 2013) e a medida que cresce o consumo de crack, aumenta a necessidade de conhecer o perfil de seu usuário e encontrar uma forma eficaz de tratamento. Muitas vezes o usuário não reconhece a necessidade da terapêutica tornando mais difícil uma possível adesão ao tratamento, sendo comum que a fissura pelo crack seja a grande responsável pela dificuldade de buscar o tratamento ou mesmo pelo abandono do mesmo (CHAVES et al., 2011).

Neste contexto, o nosso estudo apresentou como objetivo investigar os fatores motivacionais ao tratamento de usuário cocaína/crack atendidos em um Hospital Terciário de Porto Alegre.

\section{METODOLOGIA}

Trata-se de uma pesquisa observacional transversal, qualitativa e quantitativa, a partir da aplicação de instrumento de coleta de dados. A amostra $(n=9)$ foi constituída por indivíduos em tratamento no centro de dependência química de um Hospital Terciário de Porto Alegre do Rio Grande do Sul, no período de junho de 2011 até setembro de 2011, procedentes de diversos bairros de cidade e de outras cidades próximas, que tem convênio com instituição através Sistema Único de Saúde (SUS). 
Os critérios de inclusão da amostra compreenderam todos os usuários internados que aceitaram participar do estudo, sendo eles do sexo masculino, maiores de 18 anos, alfabetizados, sem comprometimentos cognitivos identificados pela psicóloga da instituição e internados pela dependência de cocaína/crack.

Os dados foram obtidos através da realização de entrevista contendo questões abertas e fechadas e após a aceitação através do Termo de Consentimento Livre e Esclarecido (TCLE), abordando histórico hospitalar, comprometimento de abuso/ dependência de droga, crises de abstinências, comprometimentos cognitivos. O tratamento dos dados obtidos procedeu-se com a tabulação no programa Microsoft Office Excel 2010 e realizou-se uma análise descritiva dos dados pelo SPSS- versão 21.0. O estudo obteve aprovação do Comitê de Ética em Pesquisa do Centro Universitário Metodista - IPA (número protocolo: 125/2011).

\section{RESULTADOS E DISCUSSÃO}

Este estudo foi realizado para identificar os fatores que motivam o adicto em cocaína/ crack a buscar tratamento hospitalar. A amostra foi composta por nove indivíduos, todos do sexo masculino com idade média de 29,77 anos. Destes, de acordo com a etnia, houve um número de $56 \%$ de indivíduos que se autodenominam brancos. Já com relação à situação conjugal, $56 \%$ eram solteiros.

Quanto à ocupação, 56\% dos entrevistados não possuíam nenhuma ocupação. Sabe-se que o crack é uma droga que atinge todas as classes sociais, não sendo ligada a marginalidade apenas, porém coloca os usuários na mesma situação socioeconômica após seu uso e dependência, sendo prejudicados a ponto de perderem o emprego (AZEVEDO et al., 2006). Quanto à escolaridade, nenhum possuía ensino superior, apenas ensino fundamental $56 \%$ e ensino médio, atualmente um dos fatores primordiais na evasão escolar e baixo rendimento por uso de drogas tornando os indivíduos mais vulneráveis. $\mathrm{O}$ nível de escolaridade afeta diretamente na inserção no mercado formal de trabalho levando a menor possibilidade financeira e como consequência exposição ao uso de drogas (SELEGHIN et al., 2011).
Em relação ao consumo de outras drogas, $67 \%$ referiram tabagismo e $89 \%$ etilistas, também foi investigado sobre a idade em que fizeram o primeiro contato com algum tipo de droga, houve um predomínio na faixa etária de 10 e 15 estes dados corroboram com outro estudo que indica a idade de primeiro uso para o álcool 13 anos e 5 meses com desvio padrão de 2 anos e 6 meses com prevalência de uso entre meninos e o uso de tabaco aparece em segundo lugar com média de idade de 12 anos e 8 meses com desvio padrão de 2 anos e 6 meses (GIACOMOZZI et al., 2012).

Os voluntários descrevem relatos sobre fatos importantes na sua vida: “Usuário 01 descreve que após uma briga com o melhor amigo que usava cocaína, fez as pazes e acabou usando cocaína com o amigo"; "Usuário 02 experimentou cocaína em uma festa onde morava"; "Usuário 03 estava preocupado com o desemprego, pressão familiar e questionamento da mãe que queria que ele casasse e, se sentindo pressionado, acabou usando a droga"; "Usuário 04 usou pela primeira vez quando iniciou a sair para a noite em festas"; "Usuário 05 fez uso após mudar de bairro, onde fez novas amizades e teve fácil acesso a drogas e armas, que acabaram o levando a experimentar a droga em um dia após matar aula"; "Usuário 06 identificou a mãe como exemplo, a mesma deixou " três linhas (ou três carreiras)" esticadas no quarto, ele cheirou uma e as outras assoprou, sendo, na ocasião, agredido pela mãe"; "Usuário 07 demonstrou como lembrança o nascimento da filha e a falta de responsabilidade que ocasionou em afastamento da família e uso de drogas"; "Usuário 08 foi influenciado pelo amigo que o convidou para cheirar cocaína e ele aceitou e, na ocasião, relata ter ficado cheirando e bebendo na casa do amigo"; "Usuário 09 acredita que iniciou por oferta do amigos quando saiam a noite, ele relata que não lembra muito bem". O uso de drogas é visto como fruto de relações familiares conflituosas com muitas brigas, discussões e mesmo uso de algumas drogas por membros da família (PAULA et al., 2014).

Todos os indivíduos relataram terem feito uso de outras drogas como solventes, maconha, anfetamina, ecstasy, entre outras. Todos os participantes referiram já terem feito uso de outras drogas junto com a coca- 
ína/crack e referiram diferença nos efeitos, sendo estes bastante particulares. A maconha aparece como uma das principais substâncias psicoativas ilícitas consumidas pelo usuário antes de ter usado pela primeira vez o crack, seguida pela cocaína consumida de forma aspirada e, a migração do uso para forma fumada, que pode acontecer pela necessidade de sentir intensificação dos efeitos (JORGE et al., 2013).

Há estudos que apontam o consumo de álcool, tabaco e maconha como as drogas mais utilizadas pelos usuários antes de experimentarem o crack e relatam ainda, o uso destas drogas associadas ao crack (HORTA et al., 2011). Muitos usuários associam o uso da maconha junto com o crack como forma de diminuir a fissura pelo crack, assim como a perda de apetite e a insônia; no entanto, o uso da maconha também é visto como adicção (RIBEIRO et al., 2010).

Em todas as situações que envolviam drogas estavam acompanhados de pessoas próximas como amigos e/ ou familiares e, quando perguntado se alguma pessoa do convívio fazia uso de alguma substância, todos os indivíduos relataram que sim, alguém próximo fazia uso de alguma droga de abuso. Segundo Paula e colaboradores (2014) o uso de drogas parece ter relação direta com a presença de conflitos familiares, violência familiar e abuso de drogas por outros membros da família, e não com a estrutura tradicional propriamente dita.

Todos os indivíduos relataram que há facilidade para obtenção da droga, não só de cocaína/ crack quanto de outras drogas ilícitas. Essa facilidade para a obtenção aparece como um facilitador para o início do consumo desta droga (JORGE et al., 2013).

Com relação à via de administração, 56\% dos entrevistados mudaram a via de administração da droga de aspirada para fumada por diversos motivos como: valor do crack mais acessível, para experimentar ou pela falta de cocaína no local de fornecimento. Os nove participantes da pesquisa referiram terem feito uso ininterrupto de cocaína/ crack por mais de 24 horas.

Sabe-se que o fim da jornada de dias do consumo de crack se dá pelo esgotamento do usuário sendo ele físico, financeiro ou psíquico, levando-os, em algum momento, a praticarem atos ilícitos para obtenção da droga, como venda de objetos pessoais e da família, tráfico de drogas e assalto à mão armada, sendo bastante comum os usuários sentirem vergonha dos atos cometidos em momentos de fissura (CHAVES et al., 2011).

Muitos usuários reportam riscos oriundos do consumo de crack, como riscos decorrentes de efeitos psíquicos como fissura e paranoia, causados pelo uso prolongado da droga; riscos físicos e riscos relacionados à ilegalidade da droga (RIBEIRO et al., 2010).

Dos entrevistados, $78 \%$ já foram internados mais de uma vez para tratamento da adicção de cocaína/ crack; $100 \%$ buscaram tratamento motivado pela família ou por motivação pessoal.

A atribuição de sentimentos negativos na família, causado pelo uso de cocaína/ crack, provoca vergonha e tristeza, destruição e sensação de estar no "fundo do poço", acabando por classificar o usuário como "sem vergonha" e vendo com descrédito a sua recuperação (PAULA et al., 2014). Mesmo com a perda do vínculo familiar, os usuários afirmam que é da família que vem a grande motivação para buscar o tratamento (PAULA et al., 2014), e isto é percebido pelos relatos dos usuários do nosso estudo:

O usuário 03 foi motivado pela família a buscar o tratamento depois de ser ameaçado de morte ao fazer um comentário onde ele morava, ele resolveu refletir e se tratar. $\mathrm{O}$ usuário 04 foi motivado pela sua vida e pela família, acabando por reconhecer a doença, no entanto, o usuário 05 foi motivado pela filha, pela saúde física e mental. 0 usuário 07 teve um voto de confiança da esposa que iria reatar o relacionamento caso o mesmo se tratasse e também por motivação pessoal, por ter vontade de mudar de vida. 0 usuário 08 resolveu buscar o tratamento após prometer para o pai que largaria a droga, ele continuou usando e só decidiu buscar se tratar quando ficou sabendo que seu pai havia morrido um ano depois. Já o usuário 09 quis ser um exemplo para o irmão mais velho, além de ficar tocado após ver a mãe chorar, foi quando decidiu se tratar, pois não quer vê-la chorar novamente.

Todos os entrevistados relaram mudanças positivas nos aspectos físicos e aumento da autoestima após a internação. $O$ consumo de crack causa emagrecimento intenso e falta de apetite, que são causados por inquietação psicomotora, supressão de ape- 
tite e caminhadas intensas no momento da fissura em busca do crack (RIBEIRO et al., 2010). Os usuários de crack adotam estratégias como meio de fugir da fissura, como mudanças no seu cotidiano, meio de convívio e até mesmo internação buscando o isolamento do meio (CHAVES et al., 2011). Esta afirmação corrobora com o achado da pesquisa que aponta que $34 \%$ dos entrevistados relataram estar sem vontade de usar a droga no momento da internação, isto se não houver contato com a droga, porém $22 \%$ dos entrevistados relataram estar com forte vontade de usar a droga durante a internação. Alguns momentos instigam o uso do crack por usuários ou ex-usuários, como: Pistas internas, que são situações em que o usuário sente vontade de usar a droga, motivado pelo reforço positivo ou mesmo por um reforço negativo de uma situação; e pistas externas, que seria a vontade se usar a droga quando ele passa por alguma situação que faz lembrar o uso, quando o usuário quer sentir mais uma vez o prazer do uso da droga ou ainda, não quer sentir o desconforto da abstinência ou pela fissura (CHAVES et al., 2011).

As limitações observadas por este estudo foram: além do número de participantes reduzido a não delimitação do tempo de internação do usuário, que pode ter influência nas respostas por estarem a pouco tempo em abstinência.

\section{CONCLUSÃO}

O estudo mostra que a motivação da busca pelo tratamento para a adicção em cocaína/ crack é bastante particular e em geral, envolvem questões emocionais, familiares e ambientais. A importância do apoio da família e a participação em grupos onde o usuário em cocaína/ crack possa buscar a manutenção do tratamento juntamente com seus familiares, pois muitas vezes a família acredita que o tratamento está finalizado e volta à rotina anterior, o que leva ao fracasso da manutenção da abstinência. Muitos grupos apoiam o uso de drogas mais leves como o cannabis para que o usuário não interrompa abruptamente o uso de cocaína/ crack e se torne mais fácil tolerar a fissura.

A adicção pela cocaína/ crack coloca os usuários em situações muito semelhante independente da si- tuação socioeconômica, deixando claro que não há diferenças relevantes entre eles. Todos passam a ter comportamento relativamente igual e não há distinção no padrão de vida quando o grau de drogadição é elevado, isto é evidenciado também em estudos anteriores. É importante a realização de novos estudos com maior número de participantes para poder identificar a circunstância em que o indivíduo faz uso de alguma substância psicoativa pela primeira vez e o que está acontecendo no seu meio familiar. Nota-se que é comum entre usuários de drogas alguma mudança de hábitos ou de habitat, assim como novos amigos que por ventura estão fazendo uso de alguma droga ilícita ou lícita no momento em que fazem uso pela primeira vez.

\section{REFERÊNCIAS}

AZEVEDO, Renata; BOTEGA, Neury; GUIMARÃES, Liliana; Crack user, sexual behavior and risk of HIV infection; Revista Brasileira de Psiquiatria; Campinas; 10(4); 139-147; 2006. BISCH, Nádia et al.; Aconselhamento telefônico para jovens usuários de Crack; Revista Gaúcha de Enfermagem; Porto Alegre; 32(1); 31-9; 2011.

CENTRO DE INFORMAÇÕES SOBRE DROGAS PSICOTRÓPICAS. V LEVANTAMENTO NACIONAL SOBRE O CONSUMO DE DROGAS ENTRE ESTUDANTES DO ENSINO MÉDIO DA REDE PÚBLICA DE ENSINO NAS 27 CAPITAIS BRASILERAS 2004; Disponível em: www.unifesp.br Acessado em: 31/03/2011.

CHAVES, Tharcila et al.; Fissura por crack: comportamentos e estratégias de controle de usuários e ex-usuários; Revista de saúde pública; São Paulo 45(6); 1168-75; 2011.

DEPARTAMENTO DE IST, AIDS E HEPATITES VIRAIS: PESQUISA NACIONAL SOBRE O CRACK: Disponível em: www.obid. senad.gov.br; acessado em 23/03/2015.

DIAS, Andréa; ARAÚJO, Marcelo; LARANJEIRA, Ronaldo; Evolução do consumo de crack em estudo de coorte com histórico de tratamento; Revista de Saúde Pública; São Paulo; 45(5); 938-48,2011.

FORMIGA, Leonel et al.; Comparação do perfil de dependentes químicos internados em uma unidade de dependência química de Porto Alegre/RS em 2002 e 2006; Revista HCPA; Porto Alegre; 29(2); 120-126; 2009.

GALLASSI, Andréa; ELIAS, Paulo; ANDRADE, Arthur; Caracterização do gasto SUS com internações de dependentes de substâncias psicoativas no período de 2000 a 2002 no município de Campinas - SP, Revista Psiquiatria Clínica; São Paulo; 35 (1); p. 2-7; 2008. 
GIACOMOZZI, Andréa et al.; Levantamento sobre Uso de Álcool e Outras drogas e Vulnerabilida de Relacionadas de Estudantes de Escolas Públicas Participantes do Programa Saúde do Escolar/ Saúde e Prevenção nas Escolas no Município de Florianópolis; Saúde Social São Paulo; São Paulo; 21(3); 612-622; 2012.

HORTA, Rogério et al.; Caderno de Saúde Pública, Rio de Janeiro, 27(11): 2263-2270; 2011.

JORGE, Maria et al,; Ritual de consumo do crack: aspectos socioantropológicos e repercussões para a saúde dos usuários; Ciência e Saúde Coletiva; Rio de Janeiro; 18(10): 29092918; 2013.

KESSLER, Felix; PECHANSKY, Flavio; Uma visão psiquiátrica sobre o fenômeno do crack na atualidade - Revista de Psiquiatria; Porto Alegre; 30 (2); p.96-98; 2008.

PESQUISA NACIONAL DE SAÚDE ESCOLAR 2012; Disponível em: www.ibge.gov.br; Acessado em 25/03/2015.
RIBEIRO, Luciana; SANCHEZ, Zila; NAPPO, Solange; Estratégias desenvolvidas por usuários de crack para lidar com os riscos decorrentes do consumo da droga; Jornal Brasileiro de Psiquiatria; São Paulo; 59(3); 210-218; 2010.

PAULA, Milena et al.; Usuário de crack em situação de tratamento: experiências, significado e sentidos; Saúde Soc. São Paulo, São Paulo; 23; n.1; 118-130; 2014.

PULCHEIRO, Gilda et al.; Crack- da pedra ao tratamento; Revista AMRIGS; Porto Alegre; 54(3); 337-343; 2010.

RIBEIRO, Luciana; SANCHEZ, Zila; NAPPO, Solange; Estratégias desenvolvidas por usuários de crack para lidar com os riscos decorrentes do consumo de drogas; Jornal Brasileiro de psiquiatria; São Paulo; 59(3); 210-218; 2010.

SELEGHIM, Maycon; OLIVEIRA, Magda; Padrão de Abuso em Usuários de Crack em Tratamento em Uma Comunidade Terapêutica; Revista Neurociência; São Paulo; 21(3); 339 348; 2013. 